\title{
3D Crime Scene Investigation
}

\author{
Gitanjali Dass ${ }^{1 *}$, Nakul Pandoh ${ }^{2}$, Hemanshu $^{3}$ \\ ${ }^{I}$ Researcher, Department of Forensic Science, CTM-IRTE, Faridabad, India \\ ${ }^{2}$ Tutor/Demonstrator, Dept. of Forensic Medicine and Toxicology, Al-Falah Medical College, Faridabad, India \\ ${ }^{3}$ Researcher, Department of Forensic Science, Punjabi University, Patiala, India \\ *Corresponding author: gitanjalidass@gmail.com
}

\begin{abstract}
There are many advancements are there in the technologies are there and one of the things which have become very famous is the 3D imaging of the technologies. There has been a widespread belief that this system is there. In this system there are different hard levels of the crime scenes that are tackled. There are lots of crime scenes which can be reconstructed. The details are kept mainly in the millimeter based techniques which have been used. The system which is used is called the 3D based imaging system. NASA the one of the famous space technologies which are there is also working in the matter to make the crime scenes to be properly investigated.
\end{abstract}

Keywords: 3D imaging, Crime scene, Investigation, 360-degree imaging.

\section{Introduction}

The main aim of this assignment is to research and evaluate the 3D crime scene Investigation with the help of the special equipment which is illustrated over here. NASA scientists are also there who are continuously trying to make the different ways through which the crime scene can be properly investigated. There are technologies that have been developed and it is very important to make use of the proper techniques and the chemical to make the 3D crime scene to be properly investigated. There are different methods that are there through which the $3 \mathrm{D}$ crime scene is investigated in this assignment.

\section{Crime Scene Imaging}

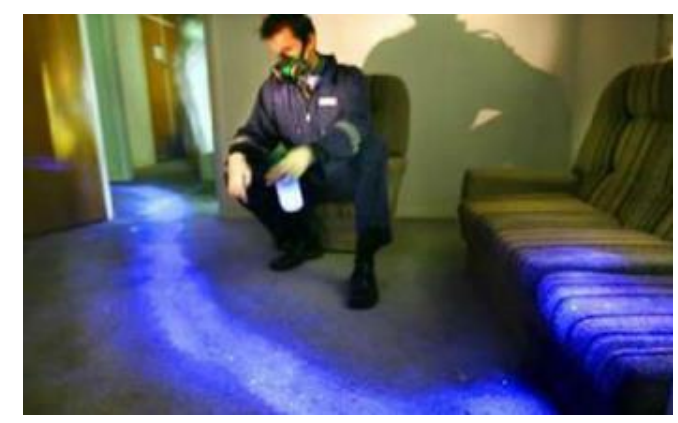

Fig. 1. Crime scene imaging (Source: Created by author)

It is called the process through which the images of the crime scene are mainly researched. It is a deliberate type of process and the main feature of the crime scene imaging is to visualize the situation of the person who was not there and the main suspect (Abate et al. 2017). There are different types of photographers are there through which the crime scene is generally visualized which are overall, midrange and the closeup (Bouchaud, 2020). There is also a type of imaging that is also there which is called 360-degree imaging (Butler, 2016). It mainly helps to analyze the main murderer and helps to make a proper visualization.

\section{The Basics of the 360 Degree Imaging}

The camera which is mainly used in the 360 Degree of the imaging in which a special rig of the multiple cameras is there which are generally used. There are also dedicated cameras there which contain multiple camera lenses (Carew et al. 2019). The camera in which there are multiple lenses and rigs are present to help make the imaging to be done in a proper way. There is a special type of method there which is called the stitching type of a method (Chase and LaPorte, 2017). It is a special type of a method through which the individual images are mainly merged into a spherical type of an image (Colwill, 2016). In this function, there are all colors' and the contrast which is there is basically calibrated with that there is a huge level of consistency there.

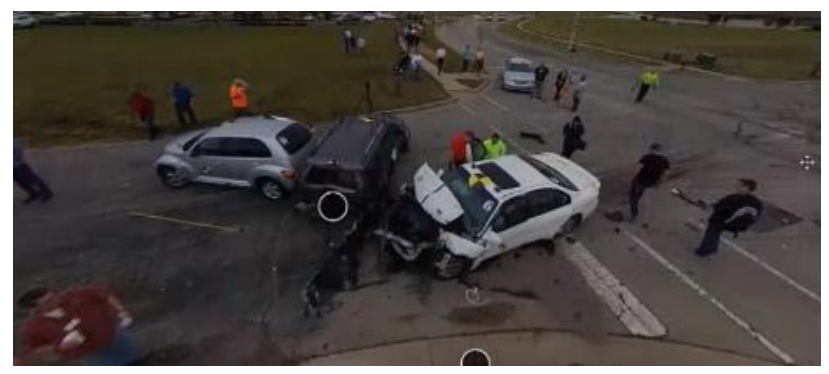

Fig. 2. 360 Degree crime scene crash (Source: Created by author)

There is a way in which the stitching can be done in a special type of way which is called the automated way (Yesodharan, 2018). There is software and the computer is there which is used in which the stitching can be done automatically (de Leeuwe, 2017). There is manual intervention there which is also there which can also be necessary. The images and the video which is captured on the 360-degree system can also be played in the smart phones as well as the computers and there are also headsets which can also be used. One of the major things which 
are very important is called the quality of the photo (Fatima, 2019). There are a variety of imaging solutions that are there in the market from different ranges.

\section{Tools Used in the 3D Crime Scene}

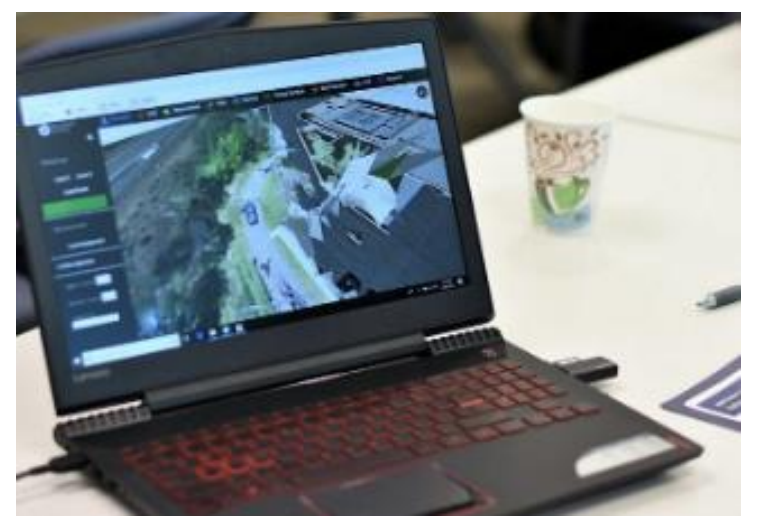

Fig. 3. 3D Hawk tool for crime scene mapping (Source: Created by author)

There is a use of a major tool there which is called as 3DHawk which can easily make the crash things to be changed into a creative 3D crime scene (Gouse et al. 2018). This is called as the special type of system which is used to make the video and the images to be converted into very high quality and the graphics (van den Eeden et al. 2016). This does help the investigator to make a proper search.

\section{Advantages of the Raw Data in the Forensic}

There are raw files there in the 3D based crime investigation and it especially makes the color of the photos to be adjusted. In case of maintaining the white balance and the setting of the contrast are also very important which are there (Jeanguenat and Dror, 2018). This mainly helps the specialist to make the adjustment to be done with a proper type of evidence to be maintained (Thompson, 2018). This is called one of the aspects through which clarity and the proper imaging can be done.

\section{Factors to Consider the User Experience}

Mainly there is only a single photo there which captures the entire scene which is of 360 degrees. It is considered to be the whole room (Jennings, 2020). There are videos which are made with the 360 imaging that also helps the crime scenes to be investigated from different angles. This is a kind of operation which is very easy and there are different types of systems there through which it can be used (Kanbar, 2016). There are two ways which are called the basics like stitching and the exporting which can be done in an automated way (Sterzik and Bohnert, 2016). There are two things which are called as the indication and the distortion which can be minimized with the use of the smart software.

\section{A. Image Considerations}

There is some consideration regarding the images is there which need to be there like which are as follows:

1. Aperture: It is called the lens or the opening of the camera through which the light generally passes in order to enter the camera (Kovaleva et al. 2020). It is especially expressed in $\mathrm{f}$ which is mainly to make the size of the opening to be illustrated. It is a special way through which the light can be controlled. It is one of the special functions of the camera through which the 360 degrees and the 3D crime scene can be investigated.

2. Field of View: It is called the open observable area which is important through which a person can see through each other. It is called as the special type of a system through which the devices can easily manage the electromagnetic radiation and to allow coverage of the area (Mendis, 2016). It is only focused on a single point or the area. It is the item which is there in the photograph can be used in the Crime scene to be properly investigated.

3. Sensor: It is a special type of a thing which detects people to make an image and is a specific type of information (Murray et al. 2017). It is called as the type of AI which can be used in the Crime scenes to make the detection of the crimes. It mainly works with the million light cavities which are there to make a record of an image.

4. ISO: It is also called as the special type of sensitivity which is used in cameras (Randolph-Quinney, 2018). It is called the ability through which the camera can absorb the light and through which there are different functions that can be changed.

5. Shutter Speed: It is called the length of the time through which the shutter of the camera is opened (Schmitz, 2016). It is called the function through which the camera spends taking a photo. This is an important aspect of the camera which helps in detecting images.

6. Resolution: It is mainly related to the size and the image graphics through which the quality of the image can be easily determined.

7. Compression: It is called the size through which an image can be compressed and make the image to be small.

These are called as the techniques through which the image can be made more enhanced and can be used in the 3D crime scene investigation.

\section{B. Practical Considerations}

There are some practical based things that are also there which need to be there to make the photo of the crime scene to be properly distinguished (Sheppard et al. 2017). Some of the things which need to be considered are Size of the photo which 
is essential. The weight age of the photo as well as the assembling parts of the photo. There are two other thighs which need to be there are weatherproof and the shockproof.

\section{Artificial Intelligence}

It is called as the special type of a system which is called as the static type of which is used to take photos. It can also be used with short based activities (Sheppard et al. 2017). Thus is the rise in the power of the technologies which can be used and make the 3D crime scene to be properly investigated.

\section{Conclusion}

It can be concluded from the above research that there are several functions required to make a proper crime scene investigation. It is properly concluded that the usage of the quality needs to be maintained which is the foremost important thing and there are some considerations there as well which also need to be maintained. There is panning and transparency is also there which is required to be done. It is also illustrated that the use of the AI will be there to make the system to be worked in a proper manner. People nowadays are making use of the 360 degrees to make the investigation to be done in a proper way.

\section{References}

[1] Abate, D., Toschi, I., Sturdy-Colls, C. and Remondino, F., 2017. A lowcost panoramic camera for the $3 \mathrm{~d}$ documentation of contaminated crime scenes. International Archives of the Photogrammetry, Remote Sensing \& Spatial Information Sciences, 42, 2017.

[2] Bouchaud, F., Vantroys, T., Grimaud, G. and Buret, P., 2020, August. Discovering Connected Objects in the Criminal Investigations. In 2020 International Conference on Omni-layer Intelligent Systems (COINS) (pp. 1-6). IEEE.

[3] Butler, J.M., 2016. International Symposium on Forensic Science Error Management.

[4] Carew, R.M., Morgan, R.M. and Rando, C., 2019. A preliminary investigation into the accuracy of $3 \mathrm{D}$ modeling and $3 \mathrm{D}$ printing in forensic anthropology evidence reconstruction. Journal of forensic sciences, 64(2), pp. 342-352.

[5] Chase, R.J. and LaPorte, G., 2017. The next generation of crime tools and challenges: 3D printing. Natl Inst Justice, 279, pp.49-57.

[6] Colwill, S., 2016. Low-cost crime scene mapping: reviewing emerging freeware, low-cost methods of 3D mapping and applying them to crime scene investigation and forensic evidence (Doctoral dissertation, Murdoch University).

[7] de Leeuwe, R., 2017. The hiatus in crime scene documentation: Visualisation of the location of evidence. Journal of Forensic Radiology and Imaging, 8, pp.13-16.
[8] Fatima, F.F.F., 2019. Forensic Photography: A Visual and Legal Record of Crime Scene. IJECI, 3(2), pp. 10-10.

[9] Gouse, S., Karnam, S., Girish, H.C. and Murgod, S., 2018. Forensic photography: Prospect through the lens. J Forensic Dent Sci, 10(1), pp.24.

[10] Jeanguenat, A.M. and Dror, I.E., 2018. Human factors effecting forensic decision making: Workplace stress and well-being. Journal of forensic sciences, 63(1), pp. 258-261.

[11] Jennings, J., 2020. Bullet Hole Characteristics, Limiting Factors, and Reconstructing Shooter Location within a Crime Scene.

[12] Kanbar, A.B., 2016. Fingerprint identification for forensic crime scene investigation. International Journal of Computer Science and Mobile Computing, 5(8), pp. 60-65.

[13] Kovaleva, A., Frolova, E. and Demidchenko, Y., 2020, May. Application of Leading and Innovative 3D Technologies for Crime Investigation. In 6th International Conference on Social, economic, and academic leadership (ICSEAL-6-2019) (pp. 458-463). Atlantis Press.

[14] Mendis, N.D.N.A., Dharmarathne, T.S.S. and Wanasinghe, N.C., 2016. Use of unmanned aerial vehicles in crime scene investigations-novel concept of crime scene investigations. Forensic Res Criminol Int J, 4(1), p. 00094.

[15] Murray, K.R., Fitzpatrick, R.W., Bottrill, R. and Kobus, H., 2017. Patterns produced when soil is transferred to bras by placing and dragging actions: The application of digital photography and image processing to support visible observations. Forensic science international, 276, pp.2440.

[16] Randolph-Quinney, P.S., Haines, S.D. and Kruger, A., 2018. The use of three-dimensional scanning and surface capture methods in recording forensic taphonomic traces: issues of technology, visualisation, and validation. In Multidisciplinary Approaches to Forensic Archaeology, pp. 115-130, Springer, Cham

[17] Schmitz, P., 2016. The use of supply chains and supply chain management in the production of forensic maps using data from a fraud case. South African Journal of Geomatics, 5(2), pp. 156-174.

[18] Sheppard, K., Cassella, J.P. and Fieldhouse, S., 2017. A comparative study of photogrammetric methods using panoramic photography in a forensic context. Forensic science international, 273, pp. 29-38.

[19] Sheppard, K., Cassella, J.P., Fieldhouse, S. and King, R., 2017. The adaptation of a $360^{\circ}$ camera utilising an alternate light source (ALS) for the detection of biological fluids at crime scenes. Science \& Justice, 57(4), pp. 239-249.

[20] Sterzik, V. and Bohnert, M., 2016. Reconstruction of crimes by infrared photography, International journal of legal medicine, 130(5), pp.13791385

[21] Thompson, T.J.U. and Norris, P., 2018. A new method for the recovery and evidential comparison of footwear impressions using 3D structured light scanning. Science \& Justice, 58(3), pp. 237-243.

[22] van den Eeden, C.A., de Poot, C.J. and Van Koppen, P.J., 2016. Forensic expectations: Investigating a crime scene with prior information. Science \& justice, 56(6), pp. 475-481.

[23] Yesodharan, R., Renjith, V., Kumar, A. and Nayak, V.C., 2018. Forensic Clinical Photography: A Game Changer in Medicolegal Investigation and Forensic Science. Indian Journal of Forensic Medicine \& Toxicology, 12(2), pp. 262-266. 